'llu. Revista de Ciencias de las Religiones

ISSN: $1135-4712$

http://dx.doi.org/10.5209/ILUR.53846

\title{
Autopsia, embalsamamiento y signos de santidad en el cuerpo de Ignacio de Loyola
}

\author{
José Miguel Hernández-Mansilla ${ }^{1}$
}

Recibido: 26 de noviembre de 2015 / Aceptado: 1 de marzo de 2016

Resumen. Las numerosas biografías que han venido apareciendo en estos últimos años sobre Ignacio de Loyola han abordado en contadas ocasiones el tratamiento post mortem que recibió el cuerpo del santo jesuita. No obstante, aquellas que sí han tratado este capítulo de la vida del Santo, no han tenido presente la riqueza descriptiva e interpretativa que proporciona la Historia de la Medicina. Estos motivos nos han llevado a confeccionar un artículo en el que se pretende reconstruir la manipulación post mortem que recibió su cuerpo. Al mismo tiempo, el presente texto pretende aventurar algunas nociones sobre los profesionales sanitarios que realizaron la autopsia y el posterior embalsamamiento del cadáver, los "signos de santidad" hallados en el organismo y los lugares en los que se conservó el cuerpo del azpeitiarra.

Palabras clave: Ignacio de Loyola; Realdo Colombo; Juan Valverde de Amusco; autopsia; embalsamamiento; litiasis biliar; santidad.

\section{[en] Autopsy, embalming and signs of holiness in the body of Ignatius of Loyola's}

\begin{abstract}
The numerous biographies on Ignatius of Loyola's that emerged in recent years have rarely addressed the post mortem treatment received by the body of the Holy Jesuit. Even more, those that actually talked about this chapter of the Saint's life did not take into account the descriptive and interpretive richness that provides the History of Medicine. Therefore, this paper aims to reconstruct the postmortem treatment received by the body of Ignatius of Loyola's. In addition, we aim to suggest some ideas about the health professionals who performed the autopsy and subsequent embalming of the corpse, the "signs of holiness" found in the body and the places where it was preserved.
\end{abstract}

Keywords: Ignatius of Loyola; Realdo Colombo; Juan Valverde de Amusco; autopsy; embalming; biliary lithiasis; holiness.

Sumario. 1. Introducción. 2. La muerte del Santo y el examen anatomopatológico. 2.1 Los signos de santidad. 3. El embalsamamiento. 4. La Chiesa di Santa Maria della Strada y la Chiesa del Sacro nome di Gesù. 5. Fuentes y Bibliografía. 5.1 Fuentes. 5.2 Bibliografía.

Cómo citar: Hernández-Mansilla, J. M. (2016), Autopsia, embalsamamiento y signos de santidad en el cuerpo de Ignacio de Loyola, en 'Ilu. Revista de Ciencias de las Religiones 21, 79-91. 


\section{Introducción}

El presente artículo tiene como objetivo reconstruir el tratamiento post mortem que recibió el cuerpo de Ignacio de Loyola. Para ello aventuraremos algunas nociones sobre los profesionales sanitarios que realizaron la autopsia; veremos los hallazgos patológicos, que pueden ser entendidos dentro de la mentalidad de la época como signos de santidad; describiremos en la medida de los posible el embalsamamiento del cadáver; y veremos finalmente los lugares en los que se conservó el cuerpo del azpeitiarra.

El 31 de julio de 1556 moría en Roma el General y fundador de la Compañía de Jesús, Ignacio de Loyola. Los miembros de la congregación decidieron que sería oportuno conservar el cuerpo de su Superior. Uno de los modos de alcanzar este objetivo era a través del embalsamamiento ${ }^{2}$. Con esta técnica la Compañía lograría perpetuar ad aeternitatem la memoria del futuro Santo.

Durante el siglo XVI el embalsamamiento fue un procedimiento técnico, empleado en el ámbito de la religión católica, entre aquellas personas que habían adquirido en vida fama de santos. Con este procedimiento se pretendía conservar el máximo tiempo posible las exequias de un difunto. Algunos de los móviles que llevaron a buscar la incorruptibilidad de un cuerpo tuvieron que ver con el hecho de la devoción y la necesidad humana de protección. En otros casos nos encontramos con que las personas que veneraron los cuerpos incorruptos creyeron experimentar una serie de beneficios o recompensas, como los favores curativos. Sin embargo, también hubo otros motivos para la preservación artificial de un cuerpo. En la tradición cristiana, el cuerpo humano es templo del Espíritu Santo, esto implica, en el seno de la religión católica, que cuando se veneran los restos de un santo o mártir, no solamente se está alabando a ese santo o mártir, sino también, y en última instancia, a su Creador. Finalmente hubo otra serie de razones de orden práctico, como comprobar el estado en el que se encontraba el cuerpo del difunto para avanzar hacia su beatificación o canonización. En el caso de Ignacio de Loyola pueden conjugarse varios de estos motivos, aunque no es posible saber con seguridad si el estado del cuerpo tras el cuarto y penúltimo traslado influyó para la beatificación en 1609 y posterior canonización en 1622 .

El General de la Compañía de Jesús murió durante el verano. Esto implicaba que había que proceder rápidamente al embalsamamiento. El calor y la humedad podían provocar que el cuerpo del fallecido pasara rápidamente de un estado de putrefacción hacia uno de corrupción, aunque no se podía señalar con precisión el momento en el que esto sucedería debido a que unos cuerpos sufrían este proceso más rápidamente que otros ${ }^{3}$. Las reglas de la Compañía dejaban muy claro el tiempo que debía trascurrir hasta dar sepultura a los cuerpos sin vida: "Provea (el enfermero), que los cuerpos de los que pasaren a mejor vida, se preparen para la sepultura, según costumbre y uso de la tierra: y que se tengan decentemente por espacio de un día natural, si por razón del mal olor, no pareciese al Superior anticipar este tiempo"4. Tal vez

2 Las primeras noticias escritas sobre el embalsamamiento provienen del antiguo Egipto y nos las trasmite el historiador griego Herodoto en los capítulos LXXXVI a LXXXIX del Libro II (Euterpe) de la Historia.

3 El médico Paolo Zacchia señalaría unos años más tarde que la corrupción del cadáver sucedía dependiendo del temperamento, la edad y la enfermedad que había padecido el cadáver. Las Quaestiones medico-legales de Zacchia están escritas entre los años de 1621 a 1651.

4 S. J. $1735,105$. 
por este motivo, menos de veinticuatro horas, no se llegó a velar por más tiempo el cuerpo de Ignacio ${ }^{5}$. Cuando hubo terminado el acompañamiento del cadáver, los religiosos de la Casa que lindaba con Santa Maria della Strada, en Via del Campidoglio, lo colocaron sobre una mesa de madera, en una de las cuatro salas del recinto ${ }^{6}$. Según señaló Pedro Ribadeneyra, el suave olor que desprendía el cuerpo del azpeitiarra inundaba toda la sala, sin embargo antes de que el cuerpo fuera embalsamado, se procedió a un examen anatomopatológico.

\section{La muerte del Santo y el examen anatomopatológico}

Los primeros testimonios de un examen anatomopatológico durante el Renacimiento provienen del médico florentino Antonio Bienivieni. Durante el tiempo que Bienivieni ejerció la medicina llevó un control estrecho de las enfermedades de sus pacientes hasta el momento mismo de practicarles la autopsia. Su obra capital en el campo de la anatomía patológica lleva por nombre De abditis nonnullis ac mirandis morborum et sanationum causis y fue publicada tras su muerte en 1507. Esta obra recoge ciento once observaciones clínicas. El caso XXXVI acerca de un endurecimiento del estómago relata: "Mi pariente, Antonio Bruno, retenía por un corto espacio de tiempo el alimento que había comido y luego lo vomitaba. Fue cuidadosamente tratado con toda clase de remedios para curar el trastorno del estómago; pero como nada le trajo ninguna utilidad, su cuerpo empezó a enflaquecer debido a la desnutrición hasta que quedó convertido en poco más que hueso y piel. Finalmente murió. El cadáver fue abierto por razones de beneficio público. Se encontró que la abertura del estómago se había cerrado y que este órgano se había endurecido en la parte inferior, con el resultado de que nada podía pasar a través de él a los otros órganos y así la muerte fue la inevitable consecuencia"7. Este episodio particular pone de manifiesto que la lesión anatómica fue algo más que un simple hallazgo casual de los anatomistas en sus disecciones ${ }^{8}$ y que el trabajo que se propusieron los doctores en el examen anatomopatológico del Santo era una práctica dentro del campo médico que comenzaba a establecerse.

Los médicos que realizaron el examen anatomopatológico y posteriormente el embalsamamiento fueron Realdo Colombo, y con toda probabilidad su discípulo más destacado, Juan Valverde, autor en las mismas fechas de la muerte del Santo, del libro de anatomía más importante en lengua castellana, titulado: Historia de la composición del cuerpo humano ${ }^{9}$. Valverde había realizado junto a Colombo exá-

\footnotetext{
P. Venturi 1951a, Vol. II, 635-636.

P. Venturi $1951 \mathrm{~b}, 15$.

Benivenius 1529, 239-240. El texto en latín dice: "Antonius Brunus affinis meus, cũ emanducatum cibũ quàm par fuerat temporis spatio contineret, \& ita ut erat incoctum reijceret omnibus medicamentos, quae stomachi uitijs adhiberi possunt, diligentissime sotus est. Verùm cum ea nihil omnino prosicerent, \& corpori ob inopiam alimenti iam absumpto uix pellis \& ossa superessent, gradatim tandem ad mortem deductus est. Quare defuncti cadauere publicae utilitatis gratia inciso, inuentũ est hominis uentriculum ita iũctis oris ad imam eius parten obcalluisse, ut cum nihil inde ad inferiora tranamittere pocverit, necesario mors subsecuta est".

8 López 1979, 4.

9 Desafortunadamente no han llegado hasta nosotros los testimonios que prueben documentalmente que Valverde estuvo presente en este acto. Sin embargo, todo apunta a ello. Su patrón era fiel seguidor de la compañía de Jesús. El mismo Ignacio escribió sobre Álvarez de Toledo en abril de 1552 “el cardenal de Santiago que es muy favorable y amigo de la Compañía nuestra ha enviado a decir que quería que la Compañía tomase cargo de un
} 
menes patológicos de grandes hombres de la iglesia entre los que se encontraba el cardenal Inocencio Cybo. En 1550 el anatomista estuvo presente en esta autopsia de la que dijo: "El cardenal de Cibo, el cual murió de un vómito de sangre, y fue abierto, y para ver donde procedía, apretábamos el estómago y luego veíamos hincharse manifiestamente el bazo, y al contrario apretando el bazo se veía manifiestamente henchir el estómago de sangre" 10 . Por otra parte, Colombo relató las autopsias de los cardenales Humberto Gambara, muerto el 14 de febrero de 1549 de un tumor en el ventrículo derecho, y Alejandro Campeggi, fallecido el 21 de septiembre de 1554 de una posible alteración intestinal ${ }^{11}$. Creemos que este examen tuvo que interesar a Juan Valverde pues el anatomista mantuvo con Ignacio un pasado común. Ambos habían sido vasallos en Castilla del señor de Amusco, el Duque de Nájera, virrey de Navarra. No olvidemos que antes de que se produjera su conversión espiritual Ignacio había servido al Duque en nombre de los intereses de Carlos $\mathrm{V}^{12}$. Incluso en esas fechas, el señor de Juan Valverde, Álvarez de Toledo, mantenía unas relaciones cordiales con Ignacio ${ }^{13}$. Por último, en la autopsia del Santo también estuvo presente el médico ferrarés Giacomo Bono Ferrarese. Por aquellos años era el encargado de la enseñanza de la botánica en el Studio Urbis ${ }^{14}$.

Cuando los anatomistas llegaron a la Casa y se dispusieron a realizar el examen post mortem y posterior embalsamamiento se encontraron con el rostro de un cadáver cuya frente era ancha y sin pliegues, ojos hundidos y párpados encogidos y arrugados. Las orejas medianas, la nariz alta y combada estaba coronada por una cabeza sin apenas cabello ${ }^{15}$. El cuerpo de mediana estatura, tenía la extremidad inferior derecha ligeramente enflaquecida y más corta que la izquierda. Por debajo de la tibia de esta pierna dañada una enorme cicatriz advertía a los anatomistas de antiguas y dolorosas intervenciones quirúrgicas ${ }^{16}$. Antes de proceder con la técnica de vaciado del cadáver los doctores buscaron las posibles causas de la muerte.

Colegio en la Universidad de Santiago, fundado por Alonso de Fonseca el cual hasta ahora parece no ha sido poblado y es menester en se lean en él algunas Ciencias”. Melón 1996, 284. El mismo Álvarez de Toledo fue a visitar al difunto el día de su muerte acompañado de un sirviente. ¿Podría ser este mismo hombre Valverde? Por otra parte, Juan Riera ha señalado sin ningún inconveniente la presencia de nuestro anatomista en la autopsia de Ignacio: "De las noticias que refiere su maestro Realdo Colombo, se confirma la presencia de Valverde de Amusco en la autopsia de San Ignacio de Loyola", Riera 1989, 25. Otros autores, como Tomás Tamayo Santos, han seguido en este punto al historiador de la medicina. Tamayo 2005, 206. Sin embargo, tal testimonio, que vincula la presencia del palentino en la autopsia de Ignacio, no existe en el De re anatomica.

10 Valverde $1556,85 \mathrm{r}$.

11 Colombo 1559, 267.

12 O’Neill 2001, Vol. I, 661.

13 García 1991, 581.

14 Renazzi 1803, Vol. I, 209.

15 El padre Pedro Ribadeneyra fue el primero en historiar la vida de este ilustre Santo. La obra fue escrita en latín en 1572, y unos años después, esto es, en 1583, se encargó de traducirla al romance y aumentarla. El libro 1leva por título Vida del P. Ignacio de Loyola, fundador de la religión de la Compañía de Jesús. En ella señaló estos rasgos fisiognómicos que la literatura posterior se ha encargado de replicar hasta la saciedad. Ribadeneyra 1583,230 r.

16 Los biógrafos atribuyen esta seña de identidad del cuerpo de Ignacio al incidente que sufrió en la defensa del Castillo de Pamplona el 12 de Mayo de 1521 cuando servía como soldado a Carlos V. En un primer momento la herida fue tratada por los cirujanos militares, aunque los huesos de la pierna quedaron mal soldados. Posteriormente, por consejo de médicos y cirujanos, los huesos fueron nuevamente recolocados, y aunque soldaron, lo hicieron de manera imperfecta. Una pierna había quedado más corta que la otra y por debajo de la rodilla un callo óseo. Este callo fue cortado a petición del enfermo, y la pierna quedó más corta y delgada, a pesar de las unturas y estiramientos que se le practicaron en un intento por corregir la diferencia de tamaño. Una reciente biografía en la que se trata este punto es la de García 2013. 
Colombo prendió el escalpelo y comenzó a atravesar las primeras capas de la epidermis en la zona abdominal en busca de la lesión anatómica. Desde nuestro punto de vista parece que quisiera alcanzar por los sentidos de la vista y del tacto el motivo de la muerte ${ }^{17}$. Ignacio murió pasadas las diez de la mañana. A las seis de la tarde Colombo, y presumiblemente Valverde, examinaban con atención el interior del abdomen ${ }^{18}$. Hoy imaginamos cómo uno de ellos limpiaba con una esponja húmeda la sangre derramada, mientras el otro se servía del escaso instrumental anatómico para mover, cortar y examinar los órganos internos ${ }^{19}$. Posiblemente ambos intercambiaron las operaciones manuales sobre el cadáver. Cristóbal Pera ha dicho sobre esas manos que son un instrumento vinculado al propio ser del hombre y que se enraízan en su conexión intelectual. Se trata de unas manos enajenadas para un fin práctico, unas manos alienadas para producir verdad y conocimiento ${ }^{20}$. Rafael Madressi ha añadido que esas manos son un instrumento que expresa una acción intelectual que se desarrolla conforme a una voluntad: la exploración de la naturaleza del cuerpo humano y el ansia por conocer y descifrar la potencia diseñadora que la naturaleza -o Dios- expresa en la producción de sus criaturas ${ }^{21}$.

En el estómago y en "las tripas" no hallaron ningún resto de comida. Como no podía ser de otra manera, lo atribuyeron a los extremos ayunos que aquel cuerpo había realizado en vida ${ }^{22}$. Un poco más hacia la derecha, el hígado mostraba a los ojos de los anatomistas la causa de los dolores que Ignacio había arrastrado pocos años después de haberse producido la conversión espiritual. Polanco señala que Ignacio había tomado desde su juventud agua fría y thorace simplicissimo para aliviar los dolores estomacales, pero este remedio nunca logró curar por completo el daño que le afligía ${ }^{23}$.

El órgano estaba endurecido, amojamado, señala Polanco en su historia de la Compañía de Jesús. Este órgano, de vital importancia, había sufrido las duras abstinencias con las que el Santo quiso estar más cerca de Dios. El padre de la Compañía, Diego de Eguía, decía que Ignacio vivía por milagro. "Dios nuestro Señor, por ser entonces necesario para la Compañía, supliendo la falta de los órganos corporales, le conservó la vida"24.

El paleodiagnóstico realizado por el doctor Alejandro Canezza, antiguo médico y bibliotecario del Ospedale Santo Spirito in Sassia, ha señalado que: "La enfermedad de Ignacio consistía en una calculosis biliar, con síntomas particulares que repercutían en el estómago. Los accesos dolorosos presentaban el carácter singular de irra-

\footnotetext{
Para conocer el procedimiento del embalsamamiento puede consultarse la obra de Pérez 1666, 100-108. MI. FN. 1943, Vol. I, 775-776.

19 Un cuchillo a modo de hoz pero no tan curvado. En medio tiene un yunque o bigornia para poder ser golpeado por un mazo de madera. También hay unos anzuelos o garfios grandes para retirar la piel y poder examinar el interior del cuerpo. Una sierra de ebanista para poder cortar los huesos. Una cuña de acero de una tercia de largo para abrir el cráneo. Aguja e hilo para cerrar el cuerpo. Para conocer más detalles de este primitivo instrumental el lector interesado puede consultar en la obra de Isidoro de Sevilla 1982, 503 editada recientemente por M.C. Díaz, M.A. Marcos y J. Oroz un análisis de estos temas médicos.

20 Pera 2003, 231-236.

21 Mandressi 2003, 44-52.

22 MI. FN. 1943, Vol. I, 776. Colombo 1559, 266-267.

23 Polanco 1898,35 . Hoy nos parece normal que el remedio medicinal no tuviera ninguna capacidad curativa. Es muy probable que uno de los remedios que el Santo utilizó para aliviar su dolencia, la thorace simplicissima, fuera un fármaco basado en polvo de momia. Para conocer este tipo de remedios el lector puede consultar: Marinozzi 2003, 501-533. Dannenfeldt 1985, 163-180.

24 MI. FN. 1943, Vol. I, 769.
} 
diarse al estómago, simulando, por eso una enfermedad de este órgano, como sucede precisamente en aquella forma de cólico biliar, denominada precisamente gastrálgica a causa de esta fenomenología"25. También en el siglo XX Gregorio Marañón se ha ocupado de analizar la vida y la muerte de Ignacio de Loyola. Marañón, apoyándose en los escasos datos que proporciona el De re anatomica de Colombo, y las noticias que recopiló el sacerdote jesuita José Antonio Laburu ${ }^{26}$, señala que el Santo sufrió una litiasis biliar y cirrosis hepática. Pero matiza que cuesta trabajo aceptar el paso de los cálculos al interior de la vena porta sin que sus numerosos biógrafos narren algún episodio que nos haga pensar en una peritonitis, ictericia o hemorragia ${ }^{27}$.

\subsection{Los signos de santidad}

Colombo relata en el De re anatomica el hallazgo de numerosas "piedras" en distintas partes del cuerpo de Ignacio: en los pulmones, en el hígado y en la vena porta. También las hay en los riñones y en la vesícula ${ }^{28}$. Habitualmente estos cálculos se encuentran en alguna vía excretora. En su gran mayoría son lisas y redondas, de varios colores. Probablemente abunden en el cuerpo del General de la Compañía de Jesús las localizadas en la vesícula que son, en casi todos los casos, de color negro (compuestos por bilirrubinato cálcico, polímeros de bilirrubina, carbonato cálcico y fosfato cálcico) y pardo (formados por bilirrubinato cálcico, con capas alternantes del mismo y sales cálcicas de ácidos grasos). Polanco había dicho en su historia de la Compañía que se le encontraron tres piedras. Sin embargo, Colombo no da en la autopsia un número exacto ${ }^{29}$.

La litiasis biliar probablemente recibió una interpretación religiosa. ¿Por qué creemos esto? Desde la Antigüedad las piedras han poseído unas características mágicas, curativas y moralizantes. Plinio asegura en la Historia Natural que en el estómago de las gallinas se forma una piedra semejante al cristal del tamaño de una judía. El naturalista romano la denominó alectoria y añadió que la gema vuelve a los hombres invencibles, y citó como apoyo de esta creencia a Milón de Crotona, portentoso atleta griego, del que señaló que pudo llevarla consigo en las competiciones haciéndolo insuperable ${ }^{30}$. Posteriormente, durante el Renacimiento, Ulises Aldrovandi dedicará un extenso análisis a esta piedra en el Libro XIV de su Ornithologiae.

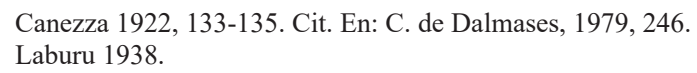
renibus colore vario, in pulmonibus, un iecore, in vena portae, ut tu tuis oculis vidisti Iacobe Bone in Venerabili Egnatio Generali congregationis Iesu. Vidi etiam lapillos in ureteris, in vesica, in intestino colo, in venis haemorhoidalibus, ataque in umbilicu: In bilis quoque vesicula, quod tamen exciderat, varij coloris, variae; figurae lapillos; \& in nonnullis complures inveni, vidiabscessum". "He extraído innumerables piedras con mis manos encontradas en los riñones, de variado color, en los pulmones, en el hígado, en la vena porta, como tú viste con tus ojos, Jacobo Boni, en el venerable Egnacio, General de la Congregación de Jesús".

29 El destino de estos fragmentos será el extravío y posterior olvido. Juan Tomás Canizaro enfermero de Ignacio presente en la autopsia confesará al Padre Lancicio en 1599 no recordar qué fue de ellas. MI. FN. 1943, Vol. III, 458. Tampoco servirán para la canonización de Ignacio como hemos comprobado en el archivo de la postulación. Nos hemos limitado a comprobar el Sommarium miracolorum B.P. Ignatii tam in vita quam post mortem, tan quae sunt in Rotulo quam extra Rotulum, tam ex processibus remissirialibus compulsorialibus quam infirmativis y podemos señalar que no aparece ninguna información referente a los cálculos biliares.

30 Plinio 1554, 657. "Alectorias vocant in ventriculis gallinaceorum inventas crystallina specie, magnitudine fabae, quibus Milonem Crotoniensem usum in certaminibus invictum fuisse videri volunt”. 
En este texto llegará a decir sobre la alectoria que se engendra en el ventrículo del capón, aunque, señalará ciertas dudas sobre las virtudes que se le han atribuido, como por ejemplo, que convierta al hombre en "un orador incisivo, decidido y agradable, y en cuanto a la mujer, que excite su libido"31.

A propósito de las virtudes curativas de las piedras preciosas, vemos que las que se crían en las entrañas y las agallas de las cabras y los venados, llamadas bezoares, fueron utilizadas durante el siglo XVI como poderosos remedios medicinales, especialmente como expelentes de todo tipo de venenos. Galeno en el mundo antiguo, Avicena en la Edad Media y Andrés Laguna en el Renacimiento les atribuyeron grandes propiedades curativas. $\mathrm{Y}$ entre aquellos modernos que mantuvieron un contacto más íntimo con las piedras bezoares procedentes del Nuevo Mundo, como por ejemplo, Nicolás Monardes, vemos que se refieren con gran admiración a su virtud curativa: "Parece cierto cosa de milagro, los efectos que una piedra sacada del vientre de un animal como un ciervo, o cabra, en tan poca cantidad dada, haga tan grandes efectos" ${ }^{\prime 2}$. Precisamente, por sus supuestas propiedades salutíferas, los hombres más relevantes de la centuria entre los que se encontraron Carlos V y Felipe II poseyeron en su colección privada estas medicinas-amuletos difíciles de procurar y de elevado coste. Concretamente el Emperador tomaba habitualmente tres gramos de esta piedra con agua de lengua de buey para controlar sus tristezas y melancolías ${ }^{33}$.

Finalmente, las piedras preciosas también recibieron virtudes morales en las obras de ciertos teólogos y naturalistas, al menos, en la del franciscano Juan Gil de Zamora. En su enciclopedia científica conocida como Historia Naturalis, Juan Gil realizó una maniobra de edificación moral a partir de los elementos que se hallan presentes en la naturaleza, entre los que encontramos las piedras preciosas. La tesis de Juan Gil es que Dios está presente en la naturaleza y mediante su examen es posible mostrar al devoto cristiano sus características metafísicas, físicas y morales. Las dos primeras propiedades dictaminan que la Naturaleza ha sido creada por Dios y que posee unos atributos como la forma, el peso, el color, etc. Mediante la tercera percibimos la bondad de Artífice que un día creó esta gran obra y hoy todavía la conserva.

De esta enciclopedia medieval solamente han llegado hasta nosotros los exámenes de las piedras que comienzan por la primera letra del alfabeto. El resto del manuscrito está extraviado. El análisis de su contenido nos revela varias sorpresas, entre ellas el tratamiento que recibe, por ejemplo, el ágata. Para el autor se trata de una piedra preciosa de múltiples cualidades, portada por reyes y grandes personajes como Eneas o Aquiles, cuyo valor se ve reflejado en ella. En perspectiva moral el ágata representa para Juan Gil el espíritu de profecía inspirada por el Señor e infundida por el Espíritu Santo ${ }^{34}$.

31 Aldrouandi 1600, 253. "Hic oratorem verbis facit esse disertum, constantem reddens, cunctisque per omnia gratum. Hic circa veneris facit incentiva vigentes; commodus uxori, quae vult fore grata marito. Ut bona tot praestet, clausus portetur in orbe".

32 Monardes 1574, 148r. Para conocer la casuística de la piedra bezoar en este autor el lector puede consultar los folios $143 \mathrm{v}^{\mathrm{o}}-148 \mathrm{r}$.

33 Monardes 1574, 146r.

34 Gil 1994, Vol. I, 166-171. "El ágata hace vencer los peligros, proporciona fuerzas al cuerpo y torna al hombre hermoso, atractivo, persuasivo, de buen color y de fácil palabra y lo protege contra los contratiempos, favorece la vista y actúa contra la sed y el veneno y cuando se quema produce un grato olor, así el espíritu, es decir, el espíritu de profecía, torna al hombre que lo posee fuerte en los peligros y en los contratiempos, grato a los hombres y a los ángeles, de visión clara en las Escrituras, nada ambicioso en las cosas mundanas, decidido ante los venenos, y con sus aromas y ungüentos los hace olorosos y de buena fama". 
Siguiendo estas noticias pensamos que las piedras contenidas en el cuerpo del Santo pudieron ser tomadas como signos visibles de Dios sobre sus criaturas. De ser así, ellas podrían manifestar que el hombre que las albergaba estaba llamado a ser el instrumento de Dios. El año de la muerte de Ignacio, la Iglesia católica buscaba caballeros cristianos que hicieran frente a las herejías que azotaban a la Europa cristiana. En este sentido, los fragmentos preciosos que se encontraron en el cuerpo de Ignacio podrían haber mostrado a los ojos de los hombres una elección divina. Según esta particular interpretación Ignacio podría ser el hombre que inspirara al resto de católicos en la nueva cruzada contra las diversas formas de herejía. Su figura podría ser a partir de entonces la un moderno Miles Christianus ${ }^{35}$. Pero esta sospecha todavía tiene que ser confirmada en nuestros días por los estudiosos de la vida y obra del Santo.

Para Marañón lo más importante de la autopsia de San Ignacio fue aquello que no pudo ser dicho por esta técnica: "Los factores espirituales que, con las largas y rigurosísimas abstinencias, contribuyeron al tránsito del caballero andante Loyola"36. Sin embargo, creemos más apropiadas las ideas de Susana Sontang sobre la enfermedad. Algunas de ellas parecen ser aplicables al caso de Ignacio y consisten en que la enfermedad mortal fue en otro tiempo una oportunidad para poner a prueba la entereza moral de un individuo. Si este superaba con nota el complicado examen, la virtud crecería mucho más en el enfermo ${ }^{37}$. ¿No ha sido precisamente ésta actitud la que le han atribuido los hombres próximos al Santo y sus comentadores posteriores cuando se han ocupado de estudiar la enfermedad y la muerte de Ignacio?

\section{El embalsamamiento}

Tras el examen anatomopatológico se procedió a realizar el embalsamamiento. Pocos anatomistas conocían con rigor este procedimiento. La técnica que emplearon muy probablemente se aproximó a la descrita por Iván Eulogio Pérez Fadrique en Modo práctico de embalsamar cuerpos difuntos ${ }^{38}$. De ser así los anatomistas trataron el calor y la humedad de las partes carnosas del cuerpo del Santo con el propósito de evitar la corrupción del cadáver. Para ello aplicaron unos remedios que tornaron el cuerpo frío y seco alcanzando así la dureza y la incorruptibilidad de ciertos objetos de la naturaleza.

Algunos posibles materiales empleados por los anatomistas para conservar el cuerpo fueron: el bálsamo, la mirra, el áloe, el azafrán, la resina, el cedro, el clavo, la sal, la cal viva, y el vinagre ${ }^{39}$. El más importante de todos estos elementos fue el

35 San Ignacio inició a los 33 años su formación académica. En Barcelona comenzó con un maestro particular, el profesor Ardebalo, el estudio de la gramática. Para conocer el latín, las cosas devotas y el estilo en el hablar se le aconsejó la lectura del primer libro publicado por Erasmo de Rotterdam: Enchiridion Militiis Christiani. El libro traducido en Alcalá en 1526 fue un manual para el caballero cristiano y contenía las herramientas necesarias para combatir en este mundo la herejía. Aunque posteriormente la Compañía de Jesús censuró los libros de este pensador.

36 Marañón 1982, Vol. VII, 410.

37 Sontang 2011, 53.

38 Un siglo más tarde, cuando se procedió a describir el arte del embalsamamiento en castellano, Iván Eulogio Pérez Fadrique, cirujano cordobés, decía en su obra Modo práctico de embalsamar cuerpos difuntos, página 26: "No me negarás el que esta obra la mayor parte de los cirujanos la ignoran, y si algo saben es sin perfección, y no los culpo, porque es tan dificultosa, y de tanto primor, que para saberla se ha de haber visto ejecutar a maestros doctos".

39 Existen otros numerosos elementos que se emplean en el embalsamamiento. El interesado en conocer estos materiales, las cantidades en las que se debían mezclar y el modo de aplicarlos puede consultar Pérez 1666, 108-123 y para detener la descomposición consultar las páginas 132-138. 
bálsamo. Los tratadistas renacentistas de origen español que se dedicaron en este tiempo al estudio de la flora y la fauna señalan que el bálsamo procedente de las Indias Occidentales era de mayor calidad que el existente en la península ibérica. Nicolás Monardes se ha ocupado de trasmitirnos la procedencia y la utilidad terapéutica de este fármaco ${ }^{40}$. Durante el Renacimiento el bálsamo se obtuvo en Nueva España de un árbol mayor que el granado. Las hojas eran similares a las ortigas, cerradas y delgadas. Los indios llamaron a este árbol xilo (myroxylon) y los españoles denominaron bálsamo al medicamento que se obtenía de él. Durante el siglo XVI existieron dos maneras de obtener el bálsamo.

En el primer caso, se realizaba una incisión en la delgada corteza del árbol. A continuación, se procedía a recolectar el escaso y pegajoso líquido blanco. Este procedimiento aseguraba un bálsamo puro, aunque muy costoso en su obtención.

La segunda manera de adquirir el bálsamo del xilo era la que empleaban los habitantes de Tierra-firme. Los indios recogían las ramas y los troncos del bosque. Seguidamente cortaban todo lo recolectado en pequeñas partes. Más tarde cocían todo en abundante agua. Una vez terminada la cocción, según arte, lo dejaban enfriar. El líquido resultante que flotaba en la caldera era el bálsamo. Ya podían recogerlo delicadamente con las conchas. Este líquido rubio, muy próximo al negro, fue el más comercializado en la vieja Europa. Por el testimonio de Nicolás Monardes sabemos que la primera vez que se vendió en España, una onza llegó a costar entre 10 y 20 ducados $^{41}$. Este mismo autor nos cuenta que, en Roma, una onza del bálsamo llegó a alcanzar un precio muy elevado: 100 ducados $^{42}$. Parece ser que solamente cuando el mercado español e italiano se saturó con este remedio medicinal, el precio descendió considerablemente, siendo entre los 3 y los 4 ducados $^{43}$.

Posiblemente los hermanos de la Compañía buscaron en la ciudad el mejor bálsamo para preservar el cuerpo de Ignacio. Al menos el más costoso de procurar era en esas fechas el que provenía del Nuevo Mundo. Sin embargo, es difícil conocer si llegaron a comprarlo. Y si así decidieron hacerlo es casi imposible saber si se trató del auténtico bálsamo de Nueva España y no un producto procedente del mercado nacional italiano. Las crónicas que han llegado hasta nosotros sobre este punto son muy escuetas y tan solo se refieren a la cantidad empleada. En ningún caso se hace mención a la procedencia de este remedio medicinal. Sobre este punto el Padre Lancicio preguntó al enfermero de Ignacio, Juan Tomás Canizaro, cuánto bálsamo se había empleado en el cuerpo de Ignacio, a lo que éste respondió: "Suficiente, ni mucho ni poco" 44 .

Colombo y Valverde evisceraron parcialmente el cadáver de Ignacio. Sabemos esto por varios motivos. Tomás Canizaro dijo a Lancicio que los intestinos fueron extraídos del cuerpo de Ignacio y sepultados en el altar dedicado a la Señora de la Compañía. Sin embargo, no hace mención a otros órganos, como por ejemplo, los pulmones, a pesar de que el testimonio de Colombo nos informa de una manipulación en estos órganos cuando buscó anomalías estructurales. En cuanto al resto de

\footnotetext{
40 Monardes $1574,9 \mathrm{r}-12 \mathrm{v}^{\mathrm{o}}$. El lector interesado en el desarrollo científico y comercial de la botánica durante el Renacimiento encontrará interesante el estudio de Pardo 1993.

41 Monardes $1574,9 v^{\circ}$.

42 Monardes 1574, 10r.

43 Monardes $1574,9 \mathrm{v}^{\circ}$.

44 MI. FN. 1943, Vol. III, 458-460.
} 
órganos que alberga la cavidad torácica, Colombo no habló de ninguna anomalía en la anatomía del corazón. Por los testimonios posteriores de los Padres de la Compañía se produce un silencio sobre este punto. Nosotros pensamos que el único órgano que conservaron estos anatomistas fue el corazón. Durante el Renacimiento no se supo con seguridad si depositarlo fuera del cuerpo del difunto o devolverlo al pecho que le vio crecer. Para los aristotélicos éste órgano representaba la casa del alma. Era el rey y señor de todas las partes del cuerpo. Además, en el caso de las personas devotas, el corazón se convertía en el Relicario de Dios. Posiblemente el corazón de Ignacio, como sucedía con el de los Pontífices, arzobispos y obispos se preservó mediante ungüentos y sutiles polvos, y fue colocado de nuevo en el pecho que un día animón ${ }^{45}$.

\title{
4. La Chiesa di Santa Maria della Strada y la Chiesa del Sacro Nome di Gesù
}

Al día siguiente, el 1 de agosto de 1556, el cuerpo del Santo fue sepultado en la parte del evangelio del altar mayor de Santa Maria della Strada ${ }^{46}$. Los hermanos enterraron a Ignacio con ornamentos sacerdotales: casulla dorada y un cáliz en las manos. Solamente faltaba una cosa más para que la labor de los anatomistas no fuera en vano. Un sepulcro con unas condiciones especiales que permitieran la conservación del cuerpo. El sepulcro debía ser idealmente frío y seco, y si esto no era posible, podía ser caliente y seco. Pero nunca húmedo.

Finalizado el rito fúnebre, tras las cinco de la tarde, los hermanos de Ignacio se dispusieron a colocar el cuerpo en una caja de madera. Finalmente metieron el ataúd en la tumba recién excavada junto al altar mayor. La piedra que colocaron encima llevaba el siguiente epitafio escrito (no inciso) ${ }^{47}$ :

\author{
D.O.M \\ IGNATIO LOYOLA FVNDATORI PRIMOQUE PRAE- \\ POSITO GENERALI SOCIETATIS IESV ALVMNI \\ EIVS AC FILII QVOS IN CHRISTO GENVIT PATRI PIEN- \\ TISSIMO ATQUE OPTIMO PRO TEMPORE POSVERVNT. \\ OBDORMIVIT IN DNO. ANNO AETATIS SVAE LXV. \\ CONFIRMATI VERO A SEDE APOSTOLICA ORDINIS QVEM IPSE
}

\footnotetext{
45 Unas veces el corazón se devolvía al pecho del difunto. En otras ocasiones no era depositado en el pecho de su propietario, sino en la tumba junto al cadáver. En esas ocasiones se colocaba en una caja de cedro, ciprés o plomo entre algodones y polvos finos. Además, en el contenedor, se labraba el nombre de su propietario. Hacia finales del siglo XVI y comienzos del XVII se aconsejaba colocarlo de nuevo en el pecho del difunto. Pérez 1666, 97-98.

El lector interesado en el comercio de reliquias puede consultar el texto de Canetti 1999, 113-153.

46 Ese día Ignacio causó dos milagros. El Padre Bobadilla quedó libre de su fiebre. Además, una niña que no pudo acercarse al cuerpo de Ignacio recobró la salud de su garganta tras aplicarle un pedazo del vestido del difunto sobre esa parte del cuerpo. MI. FN. 1943, Vol. I, 774. Para saber más milagros que obró tras la muerte puede consultarse Nieremberg 1631, 95v $\mathrm{v}^{\circ}-104 \mathrm{r}$.

Para conocer otros milagros del Santo en vida como la liberación de la posesión demoniaca, la cura de la gota coral, las visiones a distancia, la resurrección de los muertos e incluso la restitución de la salud a uno de los médicos que habitualmente lo atendían, nos referimos a Alejandro Petronio, puede consultarse Nieremberg $1631,35 \mathrm{r}-38 v^{\circ}$.

$47 \quad$ MI. FN. 1943, Vol. I, 776.
} 


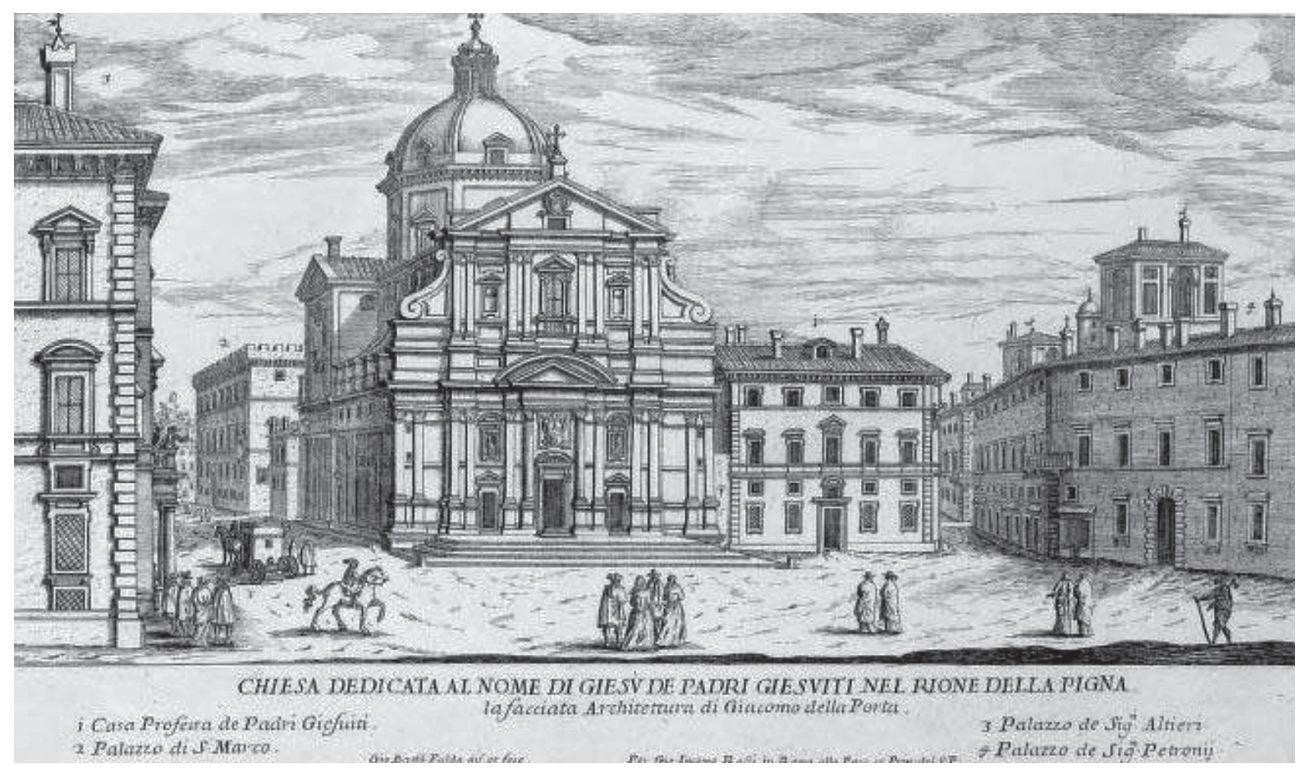

Figura 1. Fachada de la Iglesia del Santísimo Nombre de Jesús en Roma.

El templo alberga las exequias de Ignacio de Loyola. Falda 1665, 22.

\section{INSTITVIT TOTO PROPE TERRARVM ORBE DOMINO COOPERANTE PROPAGAVIT XVI. SALVTIS HVMANAE MDLVI. PRIDIE KALENDAS AVGUSTI ${ }^{48}$}

La tumba en la que fue sepultado necesitaba una claraboya por la que pasara el aire para que el cuerpo se secara más fácilmente. No sabemos si esto último fue satisfecho. Probablemente no, debido al prematuro tiempo en el que todo sucedió.

Doce años más tarde, el 31 de julio de 1568, el tercer General de la Compañía, Francisco Borgia, y cuatro asistentes, trasladaron a otra parte de la Iglesia el cuerpo de Ignacio. Todos quedaron maravillados al contemplar al padre fundador. Unos años más tarde, el 19 de noviembre de 1587, comenzaron a trasladar el cuerpo a la nueva Iglesia de la Compañía.

El quinto y último traslado tanto del cuerpo como de las reliquias acaeció en 1695. En estos traslados se reveló que el cuerpo no se encontraba en condiciones óptimas. Creemos que pudo deberse a varios motivos. Tal vez los anatomistas no ejecutaron con destreza este procedimiento. Pudo suceder que el bálsamo no fuera de la calidad deseada y de la procedencia esperada. También pudo suceder que el lugar primitivo en el que se conservó el cuerpo temporalmente no fuera el ideal, aunque todas estas posibilidades están por esclarecerse.

No sabemos cuánto dinero cobraron los anatomistas por realizar esta autopsia y embalsamamiento. Tras una búsqueda en los archivos de la Romana Domus Professa

48 “A1 Dios Óptimo Máximo. A Ignacio de Loyola, fundador y primer prepósito general de la Sociedad de Jesús, sus alumnos e hijos, a los que engendró en Cristo, al padre pietísimo y óptimo, pusieron temporalmente. Murió en el Señor en el año 65 de su vida. Y confirmado por la sede apostólica la orden que él mismo instituyó, propagó con la ayuda del Señor, por casi todo el orbe, la salvación humana. En la víspera del 1 de agosto de 1556". 
los libros de cuentas que podrían arrojar este dato no muestran ninguna noticia ${ }^{49}$. Por ahora, quien desee visitar la tumba de Ignacio puede encontrarla en la capilla dedicada al Santo que la Compañía posee en la Chiesa del Gesù de Roma. Desafortunadamente no podrá contemplarlo como sucede con tantísimos cuerpos expuestos en todo el orbe católico y en particular de la ciudad de Roma debido a su deficiente estado de conservación.

\section{Fuentes y Bibliografía}

\subsection{Fuentes}

V. Aldrouandi, Ornithologiae, Bononiae, 1600.

R. Colombo, De re anatomica, Venetiis, 1559.

A. Domínguez, L. García-Ballester (eds.), Juan Gil de Zamora. Historia Naturalis, Valladolid, 1994, Vol I.

G. B. Falda, Il nuovo teatro delle fabriche, et edificii, in prospettiva di Roma moderna, sotto il felice pontificato di N.S. Papa Alessandro VII, Roma, 1665.

D. Fernández, C. de Dalmases, Monumenta Ignatiana. Fontes narrativi de S. Ignatio de Loyola et de Societatis Iesu initiis. Narrationes scriptae ante annum 1557. Narrationes scripta annis 1557-1574. Narrationes scriptae ab anno 1574 ad initium saeculi XVII. Vita Ignatii Loyolae, Romae, 1943

S. J., Reglas de la Compañía de Jesús, y la Carta de la Obediencia de Nuestro Glorioso Padre san Ignacio, Fórumulas de los Votos, y documentos del mismo Santo Padre, Sevilla, 1735.

N. Monardes, Primera y segunda y tercera partes de la Historia medicinal, de las cosas que se traen de nuestras Indias Occidentales, que siruen en Medicina: Tratado de la Piedra Bezaar y de la yerua escuerçonera; Dialogo de las grandezas del hierro y de sus virtudes medicinales; Tratado de la nieue y del beuer frio, Sevilla, 1574.

J. E. Nieremberg, Vida del patriarca San Ignacio de Loyola fundador de la Compañía de Iesus, Zaragoza, 1631.

J. E. Pérez Fadrique, Modo practico de embalsamar cuerpos defunctos, para preservarlos incorruptos, y eternizarlos en lo posible, Sevilla, 1666.

C. Plinio Segundo, Historiae Mundi, Basileae, 1554.

J. A. Polanco, Vita Ignatii Loiolae, Matriti, 1898.

F. M. Renazzi, Storia dell'Università degli studi di Roma: detta comunemente la sapienza che contiene anche un saggio storico della letteratura romana dal principio del secolo XIII sino al declinare del secolo XVIII, Roma, 1803, Vol. I.

P. Ribadeneyra, Vida del P. Ignacio de Loyola, fundador de la religión de la Compañia de Jesús, Madrid, 1583.

M.C. Díaz, M.A. Marcos y J. Oroz (eds.), I. Sevilla. Etimologías, Madrid, 1982.

J. Valverde, Historia de la composicion del cuerpo humano, Roma, 1556.

P. Zacchia, Quaestiones medico-legales, Romae, 1651.

49 Concretamente se trata de la Romana Domus Professa 1134. El Libro de'pagamenti fatti a diverse persone per mano del P. Antonio Cesaris overo d'altri in nome della Casa Professa della Compagnia di Gesù in Roma. El resto de documentos que pueden contener algo de información sobre la remuneración que percibieron los anatomistas pertenecen a años posteriores. Todos comienzan en 1564. 


\subsection{Bibliografía}

L. Canetti, "Reliquie, martirio e anatomia: culto dei santi e pratiche dissettorie fra tarda antichità e primo medioevo". En: Micrologus 7, 1999, pp. 113-153.

K. H. Dannenfeldt, "Egyptian Mumia. The Sixteenth Century Experience and Debate". En: The Sixteenth Century Journal XVI, (2), 1985, pp. 163-180.

C. de Dalmases, El Padre Maestro Ignacio: Breve Biografía Ignaciana, Madrid, 1979.

E. García, Ignacio de Loyola, Madrid, 2013.

R. García, Santo Inácio de Loyola, São Paulo, 1991.

J. A. Laburu, La salud corporal y San Ignacio de Loyola, Montevideo, 1938.

R. Mandressi, Le Regard de l'Anatomiste: Dissections et Invention du Corps en Occident, Paris, 2003.

G. Marañón, Obras Completas, Espasa-Calpe, Madrid, 1982, Vol. VII.

S. Marinozzi, "La mummia come rimedio terapeutico nell'eta' moderna". En: Medicina nei Secoli: Arte e Scienza Vol. 15, Issue 3, 2003, pp. 501-533.

M. Melón, Gallaecia fulget 1495-1995. Cinco siglos de historia universitaria, Santiago de Compostela, 1996.

Ch. E. O’Neill \& J. M. Domínguez, Diccionario histórico de la Compañía de Jesús: biográfico-temático, Madrid, 2001.

C. Pera, El Cuerpo herido. Un diccionario filosófico de la cirugía, Barcelona, 2003.

J. Riera, Juan Valverde de Amusco y la medicina del Renacimiento, Valladolid, 1989.

S. Sontang, La enfermedad y sus metáforas, Barcelona, 2011.

P. Tacchi Venturi, La prima casa di S. Ignazio di Loyola in Roma, Roma, 1951.

P. Tacchi Venturi, Storia della Compagnia di Gesù, Roma, 1951. Vol. II.

T. Tamayo, Amusco y las nueve villas de la Tierra de Campos, Palencia, 2005. 